\title{
Response of Sonneratia apetala to Salinity in the Frame Work of Indian Sundarbans
}

\author{
Ankita Mitra ${ }^{1}$, Prosenjit Pramanick², Sufia Zaman ${ }^{2}$, Pardis Fazli ${ }^{3}$, Nabonita Pal $^{2}$ and \\ Abhijit Mitra ${ }^{4}$ \\ ${ }^{1}$ Department of Ecology and Environmental Science, School of Life Science, Pondicherry Central \\ University, Puducherry, Kalapet, India \\ ${ }^{2}$ Department of Oceanography, Techno India University, Salt Lake campus, Kolkata, India \\ ${ }^{3}$ Department of Biological and Agricultural Engineering, University Putra, Selangor, Malaysia \\ ${ }^{4}$ Department of Marine Science, University of Calcutta, 35, BC Road, Kolkata, India
}

\begin{abstract}
Estuarine salinification has been suggested a serious threat to the survival and growth of mangroves. However, there are few fine-scale temporal and spatial data set of Above Ground Biomass (AGB) of mangrove species in relation to aquatic salinity which can provide a base line definition of extant conditions. Here we provide observational data from 24 different sites in the estuarine regions of Indian Sundarbans that is a luxuriant habitat for mangroves. Three distinct sectors within this habitat differ by salinity and to some extent by the nature of substratum. The influence of salinity is highly species-specific. Hence, we have focussed on the AGB of Sonneratia apetala in these three sectors of Indian Sundarbans namely western, central and eastern sectors. In the western sector, the average AGB of the species was 36.85 tha $a^{-1}$ in 1996, while in 2005 and 2015 the mean $A G B$ were $43.17 \mathrm{tha}^{-1}$ and $49.04 \mathrm{tha}^{-1}$ respectively. In the central sector, the mean AGB of the species varied as per the order $7.83 t h a^{-1}$ (in 2015) > $2.74 t h a^{-1}$ (2005) > $0.84 t h a^{-1}$ (1996). The eastern sector of Indian Sundarbans adjacent to Bangladesh Sundarbans exhibited highest AGB in 2015 (mean value $=20.21 t$ $h \mathrm{a}^{-1}$ ) followed by 2005 (mean value $=14.72 t \mathrm{ha}^{-1}$ ) and $1996\left(\right.$ mean value $\left.=9.16 \mathrm{t} \mathrm{ha} \mathrm{h}^{-1}\right)$. In selected sectors the significant variation in AGB may be related to pronounced spatio-temporal variations of salinity. It is noted that $S$. apetala grows well in hyposaline environment compared to hypersaline central Indian Sundarbans. The study thus concludes with the lesson that salinity profile must be taken into account while developing the master plan for afforestation programme in this deltaic ecosystem at the apex of Bay of Bengal.
\end{abstract}

Keywords: Above Ground Biomass (AGB), Indian Sundarbans, Sonneratia apetala, salinity

\section{INTRODUCTION}

Mangrove ecosystems are among the most productive ecosystem on Earth with a mean production of $2.5 \mathrm{~g} \mathrm{C} \mathrm{m}^{-2}$ day $^{-1}$ (Jennerjahn and Ittekkot, 2002). The global storage of carbon in mangrove biomass is estimated to be $4.03 \mathrm{Pg} ; 70$ percent of which occurs in coastal margins from $0^{\circ}$ to $10^{\circ}$ latitude (Twilley et al., 1992). This unique halophytic vegetation under the domain of blue carbon contributes $\sim 11 \%$ of global total export to the ocean. However very little information is available on the regulatory role of salinity on blue carbon community although salinity governs the distribution and biomass of halophytes.

Mangrove forest of Indian Sundarbans is an ideal experimental bed to study the impact of salinity on the distribution and biomass of the floral species. Earlier works by researchers on this vertical reflect the inhibitory role of aquatic salinity on the AGB of mangroves (Mitra et al., 2011; Banerjee et al., 2013; Mitra, 2013; Raha et al., 2014; Mitra and Zaman et al., 2014; Mitra and Zaman, 2015). In this paper we attempt to combine information at different spatio-temporal scales which will aid in quantifying the regulatory role of salinity on the AGB of a common mangrove species, $S$ apetala inhibiting the 9630 sq.km. of Sundarban Biosphere Reserve (Indian part).

\section{Materials AND Methods}

\subsection{The Test Bed: Indian Sundarbans}

The study site is located at the apex of Bay of Bengal and encompasses about 102 islands (Mitra, 2000). 24 sampling sites were selected each in the western, central and eastern sectors of Indian Sundarbans (Figure 1). We demarcated these three sectors of Indian Sundarbans on the basis of 
secondary data sources on salinity (Mitra et al., 2009; Banerjee et al., 2013; Mitra, 2013; Mitra and Zaman, 2015). The three sectors are significantly different due to anthropological and geo-physical factors. The western sector is hyposaline due to contribution of fresh water through Farakka barrage. The reduction in fresh water flow in the central Indian Sundarbans is attributed to Bidhyadhari siltation since the late $15^{\text {th }}$ century (Chaudhuri and Choudhury, 1994). The eastern Indian Sundarbans, adjacent to Bangladesh receives fresh water from Ichaamati/Raimangal and also from upstream region.

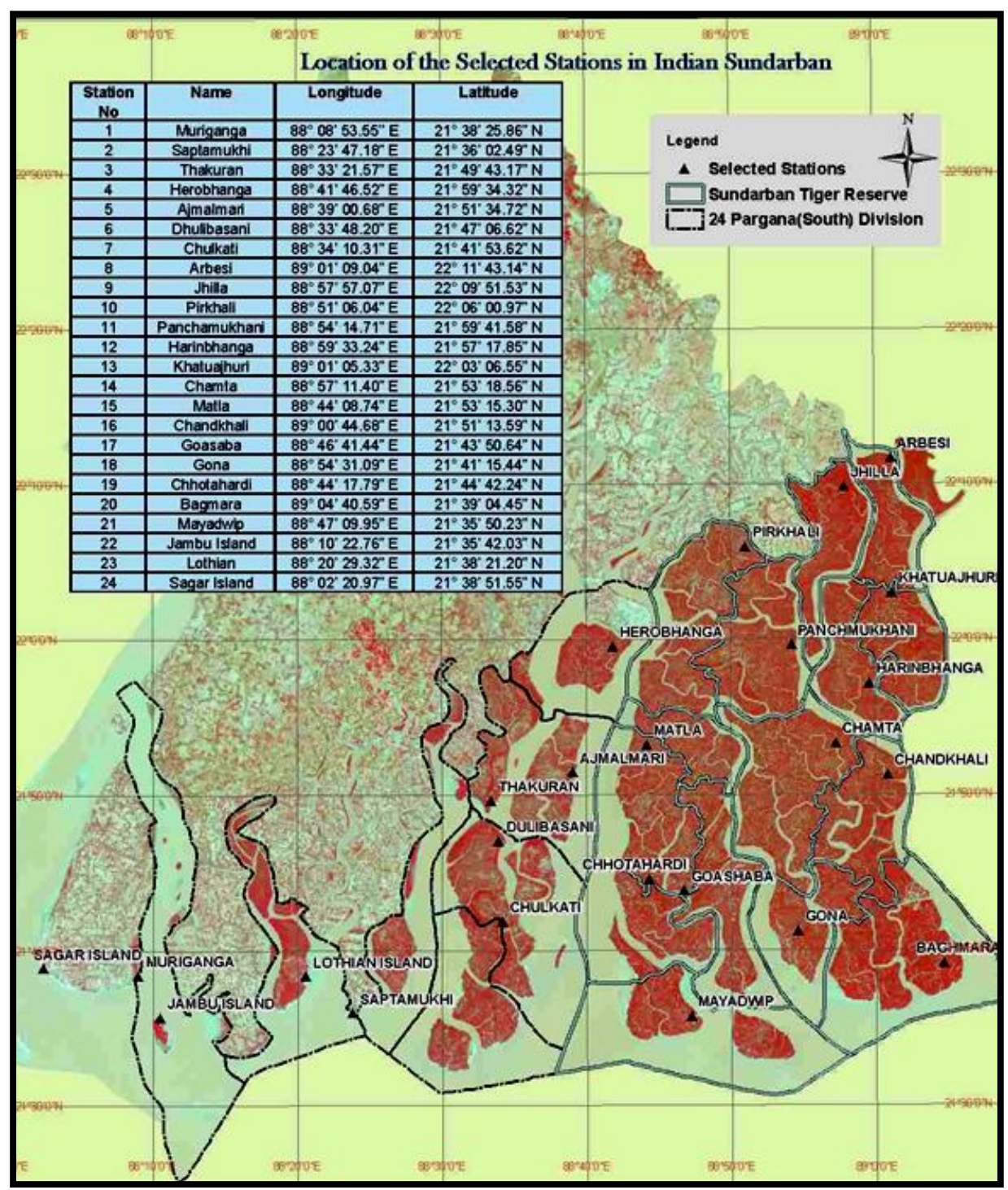

Figure1. Indian Sundarbans with 24 stations distributed in western, Central and eastern sectors; Sagar Island, Muriganga, Jambu Island and Lothian Island are within the western sector; Herobhanga, Matla, Ajmalmari, Thakuran, Dulibasani, Chotahardi, Chulkati and Saptamukhi are within the central sector and Arbesi, Jhilla, Pirkhali, Katuajhuri, Panchmukhani, Harinbhanga, Chamta, Chandkhali, Goashaba, Gona, Bagmara and Mayadwip are within the eastern sector of Indian Sundarbans

\subsection{Data Description}

We used several data sets from archives of Marine Science Department University of Calcutta, as well as published documents by Springer (Mitra, 2013; Mitra and Zaman, 2015) and TERI (Mitra and Zaman, 2015).

\subsection{Statistical Analysis}

To assess whether salinity and AGB varied significantly between sectors (western, central and eastern Indian Sundarbans) and years ANOVA was performed considering the secondary data. It is to be noted that every data point of salinity for each sector/station is the mean of 3 seasons (Premonsoon, monsoon and postmonsoon). Possibilities less than $0.05(\mathrm{p}<0.05)$ were considered statistically significant. 


\section{Results}

Figure2. Represents Station-Wise Average AGB of S.apetala

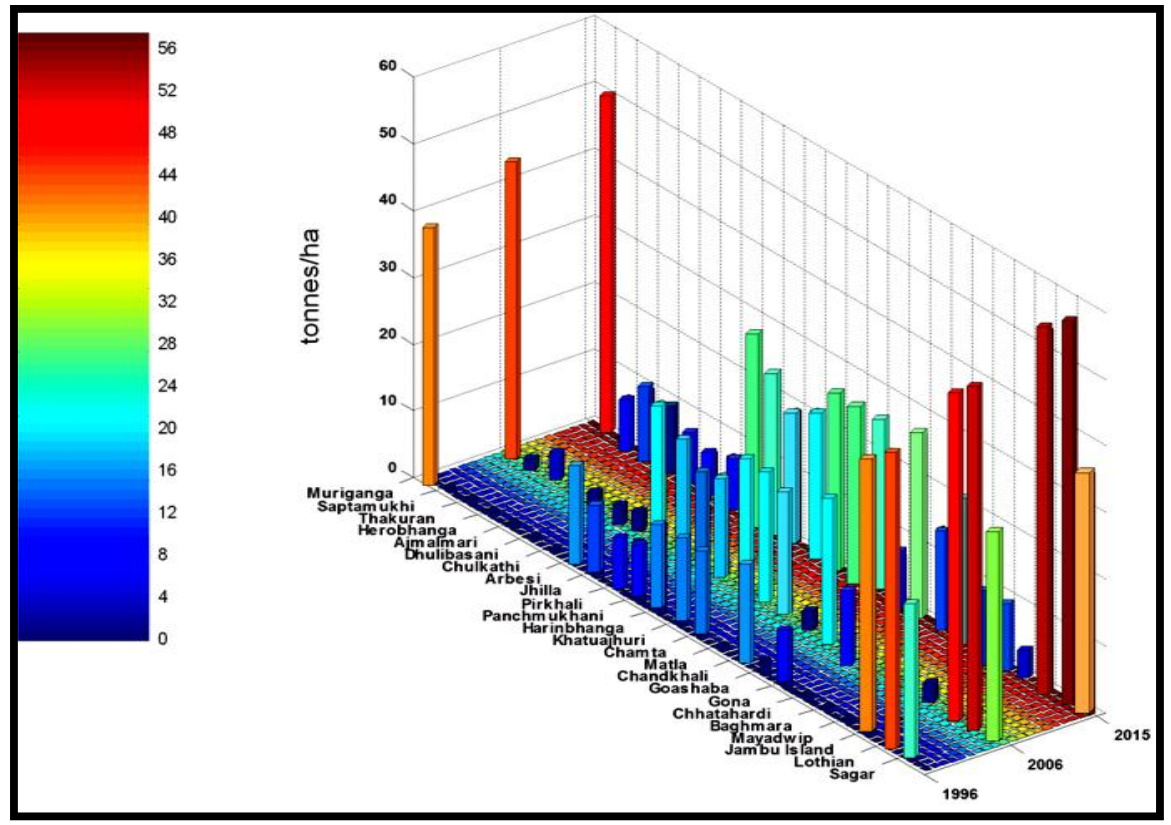

Figure2. Spatio-temporal variation of AGB of S. apetala in Indian Sundarbans

The average AGB of S.apetala in the western sector are $36.85 \mathrm{t} \mathrm{ha}^{-1}, 43.17 \mathrm{tha}^{-1}$ and $49.04 \mathrm{t} \mathrm{ha}^{-1}$ in 1996, 2005, 2015 respectively. In the central sector, the AGB values are $0.84 \mathrm{t} \mathrm{ha}^{-1}, 2.74 \mathrm{t} \mathrm{ha}^{-1}$ and $7.83 \mathrm{t} \mathrm{ha}^{-1}$ in the same years. The eastern sector of Indian Sundarbans adjacent to Bangladesh Sundarbans exhibit an intermediate average AGB of $9.16 \mathrm{t} \mathrm{ha}^{-1}, 14.72 \mathrm{t} \mathrm{ha}^{-1}$ and $20.21 \mathrm{t} \mathrm{ha}^{-1}$ in the same years. The salinity data collected from secondary data bank reflects the central sector hypersaline compared to the western and eastern sectors. The data of AGB were amenable to analysis by two-way ANOVA and significant variations between years and stations were observed (Table $1 \mathrm{~A}$ and $1 \mathrm{~B})$.

Table1A. Seasonal and Spatial Variations of Salinity in Indian Sundarbans

\begin{tabular}{|l|l|l|l|l|l|l|}
\hline Source of Variation & $S S$ & $d f$ & $M S$ & $F_{\text {cal }}$ & $P$-value & $F_{\text {crit }}$ \\
\hline Stations & 300.0044 & 23 & 13.04367 & 240003.5 & $2.5 \times 10^{-9}$ & 1.77 \\
\hline Years & 20.35583 & 2 & 10.17792 & 187273.7 & $1.13 \times 10^{-9}$ & 3.19 \\
\hline Error & 0.0025 & 46 & $5.43 \mathrm{E}-05$ & $\begin{array}{l}\text { Comment: There are significant variations in salinity } \\
\text { between years and stations (p < 0.01) }\end{array}$ \\
\hline Total & 320.3628 & 71 & \multicolumn{5}{|l}{} \\
\hline
\end{tabular}

Table1B. Seasonal and Spatial Variations of AGB of S. apetala from Indian Sundarbans

\begin{tabular}{|c|c|c|c|c|c|c|}
\hline Source of Variation & $S S$ & $d f$ & $M S$ & $F_{c a l}$ & P-value & $F_{\text {crit }}$ \\
\hline Stations & 14498.98 & 23 & 630.3904 & 247.16 & $9.65 \times 10^{-41}$ & 1.77 \\
\hline Years & 1177.005 & 2 & 588.5027 & 230.7364 & $1.04 \times 10^{-24}$ & 3.19 \\
\hline Error & 117.3249 & 46 & 2.550541 & \multirow{2}{*}{\multicolumn{3}{|c|}{$\begin{array}{l}\text { Comment: There are significant } \\
\text { variations in AGB of } S . \text { apetala } \\
\text { between years and stations }(\mathrm{p}<0.01)\end{array}$}} \\
\hline Total & 15793.31 & 71 & & & & \\
\hline
\end{tabular}

\section{Discussion}

The Indian Sundarbans in the lower Gangetic delta region at the apex of Bay of Bengal is a complex region with numerous water masses. ANOVA results exhibit distinctly different salinity profile between the western, central and eastern sectors of Indian Sundarbans (Table 1A). This variation in salinity is primarily due to the coastal influence (intrusion of salinity water from Bay of Bengal during high tide), addition of fresh water through Farakka Barrage and complete blockage of fresh water supply due to siltation of the Bidhyadhari River. These primary factors regulating the salinity profile in the present geographical locale have been addressed by several researchers (Chaudhuri and Choudhury, 1994; Mitra et al., 2011; Banerjee et al., 2013; Mitra, 2013; Mitra and Zaman, 2015; Mitra and Zaman, 2016). Because of this variation in salinity, the AGB of S. apetala has been pronouncedly affected (Table 1B), and it is of the order western sector $>$ eastern sector $>$ central sector. 
The present study has immense relevance in context to afforestation programme or eco-restoration programme as land-use changes in the Indian Sundarbans since last few decades has led to degradation of this fragile ecosystem and a loss of the goods and services they provide. Restoration is the process of assisting the recovery of an ecosystem that has been degraded, damaged, or destroyed and is critical for habitats where natural recovery is hindered. Random plantation of mangrove species often hikes up the restoration cost. The present study pinpoints clearly that $S$. apetala can be used to eco-restore the hyposaline zones of Indian Sundarbans and will be a mismatching species for hypersaline central sector.

\section{REFERENCES}

[1] Banerjee, K., Sengupta, K., Raha, A.K., Mitra, A. 2013. Salinity based allometric equations for biomass estimation of Sundarban mangroves. Biomass \& Bioenergy, (ELSEVIER), 56, 382 391.

[2] Chaudhuri, A.B., Choudhury, A. 1994. Mangroves of the Sundarbans. Volume I: India, IUCN The World Conservation Union, pp. 165.

[3] Jennerjahn, T.C., Ittekkot, V., 2002. Relevance of mangroves for the production and deposition of organic matter along tropical continental margins. Naturwissenschaften, 89, 23-30.

[4] Mitra, A., Zaman, S. 2014. Carbon Sequestration by Coastal Floral Community; published by The Energy and Resources Institute (TERI) TERI Press, India.

[5] Mitra, A., Zaman, S. 2015. Blue carbon reservoir of the blue planet, published by Springer, ISBN 978-81-322-2106-7 (Springer DOI 10.1007/978-81-322-2107-4).

[6] Mitra, A. 2013. In: Sensitivity of Mangrove ecosystem to changing Climate. Springer DOI: 10.1007/978-; 81-322-1509-7, 323.

[7] Mitra, A., Zaman, S. 2016. Basics of Marine and Estuarine Ecology, (In press).

[8] Mitra, A., Gangopadhyay, A., Dube, A., Andre, C.K.S., Banerjee, K. 2009. Observed changes in water mass properties in the Indian Sundarbans (Northwestern Bay of Bengal) during 1980 2007. Current Science, 97 (100), 1445-1452.

[9] Mitra, A. 2000. The Northeast coast of the Bay of Bengal and deltaic Sundarbans. In: Seas at the Millennium - An environmental evaluation, Chapter 62 (Editor: Charles Sheppard, University of Warwick, Coventry, UK), Elsevier Science, 2000, 143-157.

[10] Mitra, A., Sengupta, K., Banerjee, K. 2011. Standing biomass and carbon storage of aboveground structures in dominant mangrove trees in the Sundarbans. Forest Ecology and Management (ELSEVIER DOI:10.1016/j.foreco.2011.01.012), Vol. 261(7), pp. 1325 -1335.

[11] Raha, A.K., Mishra, A.V., Das, S., Zaman, S., Ghatak, S., Bhattacharjee, S., Raha, S., Mitra, A. 2014. Time Series Analysis of forest and tree cover of West Bengal from 1988 to 2010, using RS/GIS, for monitoring afforestation programmes. The journal of Ecology (Photon), Vol. 108, 255-265.

[12] Twilley R.R., Chen, R.H., Hargis, T. 1992. Carbon sinks in mangroves and their implications to carbon budget of tropical coastal ecosystems. Water, Air and Soil Pollution, 64, 265-288. 

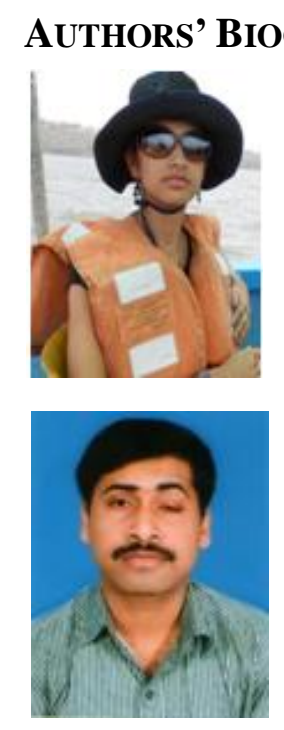

Ms. Ankita Mitra, is a postgraduate student in the Department of Ecology and Environmental Science, School of Life Science, Pondicherry Central University, Puducherry, Kalapet, India. She has to her credit 8 publications on biodiversity and climate change. Ms. Mitra received the Young Scientist Award for the year 2014 from Centre for Ocean and Environmental Studies (COES), New Delhi. She participated in several national and international seminars both within India and abroad.

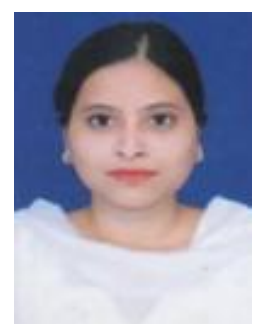

Mr. Prosenjit Pramanick, Research Scholar (presently) in the Dept. of Oceanography, Techno India University, Kolkata, India. He had completed his master degree in Biochemistry. He has to his credit about $\mathbf{5 3}$ scientific publications in various National and International journals on biodiversity, climate change, alternative livelihood etc. Mr. Pramanick received Young Scientist Award for the year 2014 from Centre for Ocean and Environmental Studies (COES), New Delhi.

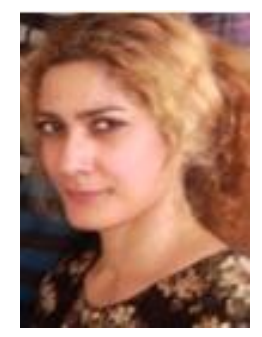

Dr. Sufia Zaman, presently serving as Adjunct Assistant Professor in the Department of Oceanography in Techno India University (Kolkata) started her career in the field of Marine Science since 2001. She worked in the rigorous region of Indian Sundarbans and has wide range of experience in exploring the floral and faunal diversity of Sundarbans. She has published 3 books on carbon sequestration, 86 scientific papers and contributed chapters in several books on biodiversity, environmental science, aquaculture and livelihood development.

Dr. Pardis Fazli, holds a $\mathrm{PhD}$ degree in Agricultural Waste Engineering from Department of Agricultural and Biological Engineering, University Putra Malaysia. Currently, in addition to cooperation with her department, she is honoured of collaboration with Professor Dr. Mitra's research group in India. She has published more than 25 scientific papers and has expertise in ecological modelling and graphics.

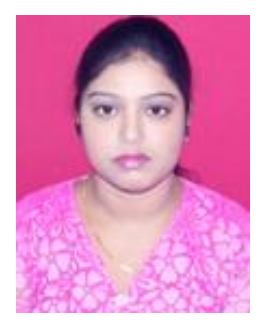

Ms. Nabonita Pal, Research Scholar in the Department of Oceanography, Techno India University is a post graduate in Biotechnology. Ms. Pal is credited to have 10 publications in National and International journals of repute. Ms. Pal has experience in working in the mangrove ecosystem of Indian Sundarbans. On behalf of Techno India University, she attended several National and International seminars. Ms Pal was honoured with Young Scientist Award in 2014 by the Centre for Ocean and Environmental Studies (COES), New Delhi.

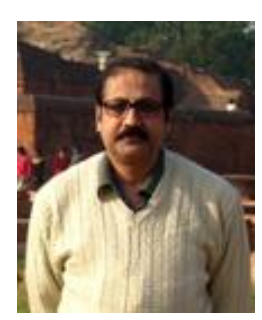

Dr. Abhijit Mitra, Associate Professor and former Head, Dept. of Marine Science, University of Calcutta (INDIA) has been active in the sphere of Oceanography since 1985. He is a Gold Medalist in Marine Science (M.Sc.) and obtained his Ph. D as NET qualified scholar in 1994. Dr. Mitra is credited to have about 350 scientific publications in various National and International journals, and 28 books of postgraduate standards. Dr. Mitra also successfully guided $24 \mathrm{Ph}$.D students. Presently his research areas include environmental science, mangrove ecology, sustainable aquaculture, alternative livelihood, climate change and carbon sequestration. 